\title{
INOVAÇÃO NOS SERVIÇOS: ESTUDO DE CASO EM REGIÕES DO INTERIOR DE PORTUGAL
}

\author{
INNOVATION IN SERVICES: CASE STUDY OF THE INLAND REGIONS OF PORTUGAL \\ INNOVACIÓN EN LOS SERVICIOS: UN ESTUDIO DE CASO DE LAS REGIONES DEL \\ INTERIOR DE PORTUGAL
}

\author{
Ana Cristina Morais Gomes (308anagomes@gmail.com)* \\ Maria Manuela Santos Natário (m.natario@ipg.pt) ${ }^{\star \star}$ \\ António Joaquim Pires Lourenço (antoniolourenco@ipg.pt) ${ }^{\star \star \star}$
}

\begin{abstract}
RESUMO
O objetivo deste estudo é obter um conhecimento mais aprofundado dos processos de inovação das empresas prestadoras de serviços, em particular em regiões de interior de Portugal. $\bigcirc$ estudo incide sobre cinco concelhos do distrito da Guarda: Seia, Gouveia, Fornos de Algodres, Celorico da Beira e Trancoso, tendo-se procurado estudar o comportamento das empresas de serviços em termos de inovação, assim como analisar e identificar os fatores associados aos melhores desempenhos inovadores. Para o efeito utilizou-se um inquérito para a recolha de informação. Os resultados da análise permitem concluir que, na região em estudo, dentro do setor dos serviços apenas 1/3 das empresas introduziu inovações no período de 2008-2012. Relativamente aos padrões de inovação nas empresas de serviços em regiões de interior, identificaram-se três perfis comportamentais: um mais inovador e proativo; outro menos inovador, com introdução de inovação apenas exigida por lei; e outro reativo, com responsabilidade social. Os fatores que estão associados a uma atitude mais proativa em termos de inovação e à melhor dinâmica de inovação são: as variáveis contextuais e as variáveis operacionais ligadas à localização e à disponibilização de tecnologias de informação; as fontes internas e de mercado, as fontes institucionais e outras fontes informais de informação utilizadas para inovar; e a falta de informação sobre os mercados como principal obstáculo à inovação. A cooperação e o apoio governamental à inovação não evidenciaram diferenças com significado estatístico para a constituição dos grupos e sobre a influência em termos de dinâmica de inovação.
\end{abstract}

Palavras-chave: Inovação, Processos de Inovação e Inovação nos Serviços.

\begin{abstract}
This study aims to obtain a better understanding of innovation processes in the service sector, particularly in the inland regions of Portugal. Thus, the project aims to study innovation in companies providing services in five counties in the district of Guarda - Celorico da Beira, Fornos de Algodres, Gouveia, Seia, and Trancoso - not only to analyze their innovation processes but also to identify behavioral patterns of innovation and the factors that are associated with the best innovative performance of these companies. To this purpose, data was gathered through a survey. Based on an analysis of the results, only $1 / 3$ of the companies of the service sector had introduced innovations between 2008 and 2012 in the inland
\end{abstract}




\section{Egitania}

$s$ c i e $\Omega$ c i a

regions. As for innovation of the companies under study, three behavioral profiles were revealed in terms of the dynamics of innovation: the first,one is more innovative and proactive; the another that is the least innovative, with introduction of innovation restricted to that required by law; and the final profile which is reactive, demonstrating social responsibility. The factors associated with a more proactive attitude in terms of innovation and with the best dynamics for innovation are those contextual and operating variables linked to the location and availability of information technologies; internal and market sources, institutional sources and other informal sources of information used to innovate. A lack of information on the markets was found to be the main obstacle to innovation. Cooperation and government support for innovation showed no statistically significant differences either for the formation of these profiles or on the influence of dynamics in terms of innovation.

\section{Keywords: Innovation, Processes of Innovation, Innovation in Services.}

\section{RESUMEN}

Este estudio tiene como objetivo obtener una mejor comprensión de los procesos de innovación en el sector de los servicios, sobre todo en zonas de Portugal hacia el interior. El estudio se centra en cinco municipios del distrito de Guarda: Seia, Gouveia, Fornos Algodres, Celorico da Beira y Trancoso, y se pretende estudiar el comportamiento de las empresas de servicios en términos de innovación y analizar e identificar los factores asociados con un mejor desempeño innovador. Los resultados del análisis permiten concluir que sólo un tercio de las empresas del sector servicios ha introducido innovaciones entre 2008-2012, en las regiones del interior. En cuanto a los patrones de innovación en las empresas de servicios en las regiones del interior, se identificaron tres perfiles de comportamiento: el grupo 1, más innovador y proactivo; grupo 2, el menos innovador, y el grupo 3 reactivo y responsabilidad con social. Los factores que se asocian con una postura más proactiva en términos de innovación, y por lo tanto la mejor dinámica de la innovación son: variables contextuales y variables de funcionamiento vinculados a la ubicación y disponibilidad de tecnologías de la información; fuentes internas y de mercado, fuentes institucionales y otras fuentes informales de información, que se utilizan para innovar y la falta de información sobre los mercados como el principal obstáculo para la innovación. La dinámica de la cooperación y el apoyo gubernamental a la innovación no mostraron diferencias estadísticamente significativas para la formación de clusters.

Palabras-llave: Innovación, Procesos de Innovación, Innovación en los Servicios.

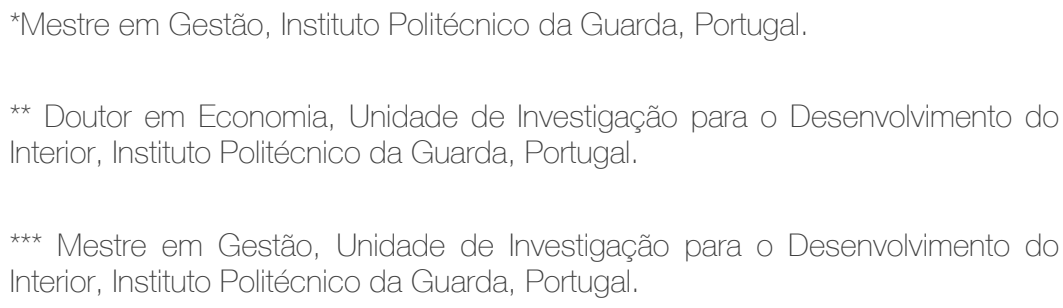




\section{Egitania \\ $s$ c i e $\Omega$ c i a}

\section{INTRODUÇÃO}

A inovação é essencial para promover a competitividade e sustentabilidade de qualquer organização. Ela é caracterizada por ser um processo de mudança que está associada ao aparecimento das novas tecnologias, mas também ao aparecimento e evolução de novos produtos, conceitos e serviços e é de extrema importância para todas as empresas inclusive as dos serviços.

Deste modo, considerou-se importante analisar a temática de inovação em particular de serviços, no sentido de se perceber o processo de inovação destas empresas. A inovação em serviços, segundo o Manual de Oslo (OCDE, 2005), é organizada de forma menos formal, possuindo uma natureza mais incremental, sendo menos tecnológica do que a inovação de produtos.

A inovação dos serviços tem vindo a assumir um papel importante e crescente nas economias a nível global, resultado do aumento do peso do setor dos serviços nas atividades económicas dos países principalmente dos mais desenvolvidos e por este setor ser o maior empregador nestas economias. Este setor assume um papel importante também nas regiões de baixa densidade populacional visto que assume um peso extremamente importante no que diz respeito à empregabilidade, ao mesmo tempo que vai estimulando o desenvolvimento dessas regiões.

Face ao exposto, pretende-se analisar os processos de inovação das empresas prestadoras de serviços de cinco concelhos do distrito da Guarda: Celorico da Beira, Fornos de Algodres, Gouveia, Seia e Trancoso. Em particular, pretende-se analisar se estas empresas têm introduzido inovações e identificar padrões de comportamento, que ajudem posteriormente na construção de políticas adequadas a promover a inovação nesta região. A escolha e preferência por estes concelhos deve-se ao facto destes serem próximos e contíguos, pertencerem a um distrito do interior do país, com caraterísticas e especificidades que deverão ser tidas em conta aquando da definição de políticas de inovação de âmbito territorial.

O artigo está estruturado em seis pontos. Após a introdução, no ponto dois efetua-se uma breve revisão bibliográfica relativa à inovação nos serviços. No terceiro ponto apresentam-se as hipóteses a testar e no ponto quatro a metodologia: fontes de dados e métodos de análise utilizados. No ponto 5 apresenta-se o tratamento de dados e os principais resultados obtidos. Finalmente, no ponto seis discutem-se as conclusões, as implicações e as limitações, sugerindo-se pistas para futuras investigações. 


\section{Egitania}

s c i e $\Omega$ c i a

\section{INOVAÇÃO NOS SERVIÇOS}

\subsection{Conceito de Inovação nos Serviços}

Segundo Miles (2001), desde os anos 60 do século XX, que se tem registado uma evolução na literatura sobre a inovação nos serviços. Todavia, as primeiras análises aos processos de inovação nos serviços só aparecerem há cerca de 40 anos, com os trabalhos de Gershuny (1978) e Barras (1986), relativos ao impacto das novas tecnologias sobre os serviços e só na década de 90 é que surgiram os primeiros estudos sobre os padrões de inovação neste setor (Camacho e Rodríguez, 2005).

Como referem Sarkar e Carvalho (2006) o setor dos serviços ainda é um setor pouco investigado no que diz respeito à inovação, o que se justifica pelas características próprias deste setor, nomeadamente a heterogeneidade das atividades, a imaterialidade e intangibilidade. Nos serviços, a inovação está frequentemente relacionada com o conhecimento tácito, implícita à empresa, muitas vezes relacionando com as competências dos recursos humanos. A inovação assume uma dimensão não tecnológica, mais intangível e, por conseguinte, mais difícil de medir.

As características de intangibilidade associadas aos serviços influenciam quer os processos de inovação das organizações, quer a forma de medir os resultados da inovação (Bloch e Bugge, 2013). Deste modo, a inovação neste setor baseia-se, muitas vezes, em novas formas de organizar os recursos humanos, na promoção dos relacionamentos de carácter informal para potenciar a partilha de informações e desenvolver o espírito de grupo, na redução do uso de determinados materiais e poupança de energia ou consumíveis em alterações nas estratégias do marketing, na criação de novos interfaces com os clientes, de novos canais de distribuição, de novas técnicas de gestão ou aumento de flexibilidade das empresas (Sarkar e Carvalho, 2006).

Dadas as caraterísticas dos serviços, a inovação neste setor pode ter várias conotações como se pode verificar na Tabela 1.

\begin{tabular}{|l|l|}
\hline Autor & Definição \\
$\begin{array}{l}\text { Sundbo e Gallouj } \\
\text { (1999: 9) }\end{array}$ & $\begin{array}{l}\text { "Inovação nos serviços refere-se essencialmente a pequenos } \\
\text { ajustamentos nos procedimentos de carácter incremental e } \\
\text { raramente radical. O tempo necessário para o desenvolvimento } \\
\text { da inovação nos serviços é geralmente curto (...). O processo } \\
\text { de inovação nos serviços é normalmente muito prático." }\end{array}$ \\
\hline OECD (2000: 16) & $\begin{array}{l}\text { "Comparativamente com a indústria a maioria das inovações } \\
\text { nos serviços são não tecnológicas e resultam de pequenas } \\
\text { me l l o r i a s incrementais no processo e nos procedimentos } \\
\text { que não requerem investigaçãa e desenvolvimento (I\&D) } \\
\text { formal." }\end{array}$ \\
\hline
\end{tabular}




\section{Egitania}

$s$ c i e $\Omega$ c i a

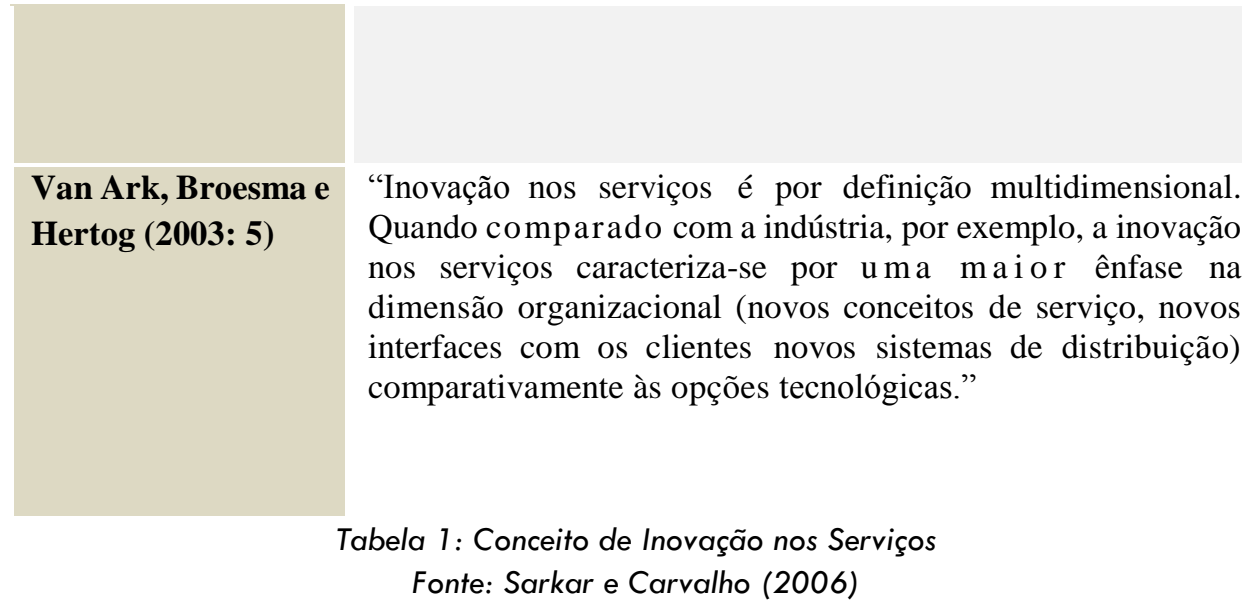

Os principais períodos de investigação sobre a inovação nos serviços, segundo Salter e Tether (2006) são os seguintes: negligência, assimilação, demarcação e síntese. Estas abordagens desenvolvidas por Sarkar e Carvalho (2006) tiveram por base diversos estudos realizados sobre a temática (Coombs e Miles, 2000; Camacho e Rodriguez, 2005; Tether, 2005; Drejer, 2004; Miles, 2005; Vries, 2006).

A abordagem negligência ocorreu até aos anos 80, sendo que até esta data pouca investigação sobre a inovação nos serviços tinha sido realizada e centrava-se apenas na indústria. Neste período, e de acordo com Adam Smith (1776) era a riqueza material que importava e era na indústria que se verificavam os avanços tecnológicos sob a forma de novos bens ou equipamentos. Segundo esta abordagem a inovação era entendida como avanços que ocorriam na indústria. O seu desenvolvimento para identificar e medir as inovações servia apenas para reforçar o entendimento de que os serviços não atraiam as novas tecnologias. A perspetiva de negligência continua presente até aos dias de hoje, pois relativamente às pesquisas sobre inovação em serviços, esta continua a estar relativamente "à parte".

A abordagem de assimilação apareceu no início dos anos 80, resultado do contínuo crescimento dos serviços nas economias avançadas, o que torna cada vez mais difícil ignorálos. Esta fase foi marcada pela tentativa de estudar a inovação nos serviços através do setor transformador, utilizando os pressupostos e as ferramentas conceptuais desenvolvidos para compreender a inovação na indústria. Neste período Barras (1986) tenta desenvolver uma teoria para a inovação dos serviços partindo do princípio que a aplicação das novas tecnologias nos serviços e a utilização de uma tecnologia industrial adequada às atividades do setor, ajuda a reorganizar partes importantes do trabalho do setor dos serviços.

A abordagem de demarcação teve principal destaque a partir dos anos 90. A maioria das pesquisas feitas nessa época era centrada na inovação organizacional e na inovação em serviços baseadas em conhecimento. Esta abordagem considera que o setor dos serviços é diferente da indústria transformadora, pelo que o estudo da inovação nos serviços exige novas perspetivas devido às características intrínsecas aos próprios serviços. Estas pesquisas voltadas para o desenvolvimento de ferramentas conceptuais e empíricas são mais sensíveis às características dos serviços e ao seu alto nível de interação com as pessoas. Neste contexto, 


\section{Egitania}

$s$ c i e $\Omega$ c i a

Drejer (2004) refere que se tem gerado muita polémica à volta desta linha de pesquisa, argumentando que o conceito de inovação deve envolver pelo menos um elemento de mudança tecnológica e não deve ser estendido para toda a mudança organizacional. Como consequência, nesta fase Sundbo e Gallouj (1998) procuraram estudar e identificar diferentes padrões de inovação de serviços.

A abordagem síntese surgiu nos finais dos anos 90, e ainda permanece até aos dias de hoje, sendo aceite pela maioria dos investigadores destas temáticas. Esta perspetiva integra as abordagens anteriores, reconhecendo que a inovação deve centrar a atenção nos serviços e nos elementos de inovação, que são relevantes tanto para os serviços como para a indústria. Nesta abordagem, a investigação sobre inovação nos serviços é motivada pelo tamanho dos serviços e pela necessidade de desenvolver uma compreensão mais completa da inovação dessas atividades, mas também é motivada pelo desejo de entender a inovação em contextos que não são dominados por desenvolvimento de tecnologias fixas. Estas abordagens especificam que a inovação nos serviços difere da inovação nos produtos, devido às características próprias dos serviços, exigindo assim modelos específicos para este setor.

Djellal et al. (2013), não consideram a abordagem da negligência, mas introduzem, além das anteriores referidas, a perspetiva de inversão (Gallouj, 2010), imediatamente anterior à síntese ou integradora. A abordagem da inversão pode ser entendida com a "vingança" ("revenge" no original de Djellal et al. 2013), do setor de serviços. Por oposição aos estudos que retratam as indústrias de serviços como os setores mais atrasados (desfasados), com baixo teor tecnológico, a abordagem inversão assume (algumas) indústrias de serviços como sendo fontes de inovação para toda a economia. Este papel normalmente é desempenhado por grandes empresas de serviços que mobilizam os seus fornecedores (por exemplo, a retalho e as telecomunicações). Todavia esta perspetiva, frequentemente, enfatiza o papel ativo de certos KIBS (Knowledge-Intensive Business Services) na inovação de outros setores. Os serviços de consultoria, de design, de engenharia, de Investigação e Desenvolvimento e as tecnologias de informação são inputs importantes para promover e estimular a inovação dos seus clientes.

Do exposto pode concluir-se, de acordo com Gallouj \& Weinstein (1997), que a análise da inovação no setor dos serviços se torna difícil principalmente devido a dois fatores: primeiro, porque as teorias da inovação foram feitas principalmente para o setor da indústria e não dos serviços; e segundo, porque não é fácil detetar as mudanças nos serviços devido às suas características.

Com efeito, as empresas adotaram as novas tecnologias desenvolvidas pela indústria transformadora, com o propósito de aumentar a eficiência dos respetivos processos e, posteriormente, a qualidade dos serviços (Silva et al. 2010; Toivonen e Tuaminen, 2009). Assim, relativamente à inovação nos serviços, o primeiro estudo foi apresentado por Barras (1986), e designado por teoria do "ciclo reverso do produto" em 1986, procurando articular os modelos de inovação com a geração das novas tecnologias de informação e comunicação (TIC) (Djellal et al. 2013). 


\section{Egitania}

$s$ c i e $\Omega$ c i a

De acordo com Barras (1986), o ciclo de inovação no setor dos serviços assume uma forma inversa do tradicional ciclo de inovação industrial: a inovação do processo precede a inovação dos produtos, o qual designou de "ciclo de inovação reversa". Ao contrário do que ocorre na indústria manufatureira, a inovação em serviços ocorre simultaneamente com a própria prestação de serviços (Silva et al. 2009).

Dentro do ciclo de inovação reversa, a inovação em serviços passa por três estágios (Silva et al. 2009): primeiro estádio - Melhoria da eficiência; segundo estádio - Melhoria da qualidade; e terceiro estádio - Novos produtos (serviços).

Dessa forma, uma inovação radical na prestação de serviços ocorreria após sucessivas inovações inicialmente com foco na eficiência e em seguida na qualidade, seguindo a evolução contrária do processo desenvolvido na indústria (Barras, 1986; Silva et al. 2009; Fonseca, 2010; Djellal et al. 2013, Salter e Tether, 2014).

Para além das características mencionadas, Hipp e Grupp (2005), citados em Silva et al. (2009), consideram ainda o fator humano; a organização do processo de inovação, o processo de inovação contínua, a interação com o consumidor, a estrutura das empresas de serviços e as questões regulatórias. Destacam ainda a questão da inovação contínua também abordada por Barras (1986).

A simultaneidade entre as atividades de inovação e de prestação do serviço onde decorre, a inseparabilidade entre cliente e prestação do serviço, sendo por vezes o próprio cliente uma fonte de ideias para a inovação (Kotler, 2000; Churchill e Peter, 2000, citados em Silva et al. 2009), são elas também caraterísticas próprias dos serviços que condicionam todo o processo de inovação.

\subsection{TIPOS DE INOVAÇÃO NOS SERVIÇOS}

Sundbo e Gallouj (1998) e Barata (2011) dividiram a inovação nos serviços em 5 categorias, sendo as seguintes:

- Inovação do produto - entendida como um novo serviço ou produto cuja venda implica a prestação de serviços. Também se caracteriza pelas aptidões e competências envolvidas no design e na fabricação dos produtos;

- Inovação do processo - origina uma mudança num ou mais procedimentos para produzir ou prestar um serviço. Esta inovação caracteriza-se por deter aptidões e competências envolvidas no design e nas operações de produção e processos de distribuição;

- Inovação organizacional - como uma forma de gestão e organização, caracteriza-se por deter dois tipos de competências: (i) competências e aptidões envolvidas no design e operacionalização da informação e na coordenação dos processos; (ii) competências ou aptidões envolvidas na gestão estratégica e do conhecimento e na transformação competitiva das empresas. O primeiro tipo de competências associa-se ao processo administrativo, enquanto o segundo tipo se interliga com o negócio; 


\section{Egitania}

$s$ c i e $\Omega$ c i a

- Inovação de mercado - quando há alterações ao nível do mercado; por exemplo, o surgimento de um novo produto induz a criação de um novo segmento de mercado;

- Inovação ad hoc - a inovação ad hoc, ou seja, aquela que acontece por adaptação às peculiaridades e necessidades de cada cliente ou situação.

O Community Innovation Survey (CIS) aos serviços contemplou apenas os dois primeiros tipos de inovações nas suas pesquisas, a que diz respeito aos novos ou melhorados "serviços" e/ou novos melhorados métodos de produção ou fornecimento do serviço.

\subsection{OBJETIVOS PARA INOVAR NOS SERVIÇOS}

Os objetivos que levam as empresas a inovarem podem relacionar-se com produtos, mercados, eficiência, qualidade ou capacidade de aprendizagem e de implementação de mudanças. A identificação desses motivos e a sua importância auxiliam no exame das forças que conduzem a atividade de inovação como a competição e as oportunidades de entrada em novos mercados (OCDE, 2005).

Segundo o CIS (UE, 2010), são vários os objetivos que levam ao desenvolvimento e à introdução de inovações, nomeadamente:

- Alargar a gama de produtos (bens e/ou serviços)

- Substituir produtos ou processos desatualizados

- Entrar em novos mercados ou aumentar a quota de mercado

- Melhorar a qualidade dos produtos (bens e/ou serviços)

- Melhorar a flexibilidade na produção (de bens e/ou serviços)

- Aumentar a capacidade de produção (de bens e/ou serviços)

- Reduzir os custos do trabalho por unidade produzida

- Reduzir o material e a energia usados por unidade produzida

- Reduzir o impacto ambiental

- Melhorar a saúde e a segurança do pessoal ao serviço

Estes vários objetivos que levam as empresas, em geral, a inovar, também se aplica, ao setor dos serviços. Deste modo, pode afirmar-se que as empresas de serviços têm diversos objetivos para inovar, embora a maioria deles estejam relacionados com o aumento da satisfação dos seus clientes ou com a otimização e rentabilização dos recursos.

Geralmente por de trás de uma inovação, seja ela planeada ou ocasional, está sempre um objetivo que se pretende alcançar. Em alguns casos passa por um simples reajustamento ou implementação algo novo. Noutros casos, prende-se com a necessidade de a empresa se reajustar à conjuntura atual a fim dos seus produtos (serviços) não ficarem obsoletos e de estar preparada para satisfazer as necessidades dos seus clientes. 


\section{Egitania}

$s$ c i e $\Omega$ c i a

\subsection{FONTES DE INOVAÇÃO E COOPERAÇÃO NOS SERVIÇOS}

Como fontes da inovação, ou seja, fontes de informações de ideias para inovar, pode ainda encontrar-se, seguindo o CIS (2010 e 2012), a seguinte tipologia:

- Fontes Internas

- Dentro da própria empresa ou do grupo a que esta pertence

- Fontes do Mercado

- Fornecedores de equipamento, materiais, componentes ou Software

- Clientes ou consumidores

- Concorrentes ou outras empresas do mesmo setor de atividade

- Consultores, laboratórios ou instituições privadas de I\&D

- Fontes Institucionais

- Universidades ou outras instituições do ensino superior

- Laboratórios do Estado ou outros organismos públicos com atividades de I\&D

- Outras Fontes

- Conferências, feiras, exposições

- Revistas científicas e publicações técnicas/profissionais/comerciais

- Associações profissionais ou empresariais

As fontes de informação contribuem para a introdução de novos projetos de inovação ou para a concretização de projetos já existentes. Devido à variedade e complexidade da inovação e do processo de inovação, as organizações são obrigadas, cada vez mais, a serem seletivas no que concerne às diferentes fontes de informação existentes e a utilizar.

Essas fontes podem ser internas à empresa que desenvolve ou melhora o processo de produção do produto/serviço, ou podem surgir através de ideias dadas pelos clientes de coisas que gostariam de ter ou que fossem feitas de maneira diferente, pois sendo eles os consumidores ninguém melhor que os próprios para informar a empresa sobre as suas necessidades. Clientes e fornecedores desempenham então um papel importante no processo de inovação uma vez que proporcionam habilidades e conhecimentos complementares aos já existentes, ajudando a mitigar os riscos associados com o desenvolvimento e adoção da inovação pelo mercado (Mention, 2011).

Os fornecedores são muitas vezes fulcrais nestas novas descobertas alertando ou simplesmente dando a conhecer o que de novo está a aparecer no mercado. As fontes informação para inovar também pode advir de feiras, mostras de produtos ou de simples pesquisas em redes de informação computacionais, que nos dias de hoje são essenciais para a atualização constante, sendo uma forma de a própria empresa se manter atualizada sobre os produtos/serviços que estão em alta ou que são simplesmente novos para aquele mercado.

As instituições de ensino superior e as instituições de investigação, através das suas pesquisas fazem "descobertas" muito importantes para as empresas, permitindo-lhes melhorar ou desenvolver algo novo e ajudando a satisfazer as necessidades dos seus clientes, tornando-se elas próprias fontes ricas de informação, embora com um caráter mais formal e institucional. As 
relações com universidades, centros de pesquisa, laboratórios e outras entidades privadas podem fornecer às empresas pesquisa avançada, conhecimento científico ou de formação (Mention, 2011).

Do mesmo modo, também os concorrentes podem ser fontes importantes de inovações, aprendizagem organizacional, produtos complementares, capacidades e recursos críticos (Mention, 2011). A busca de informação aos concorrentes, geralmente é motivada pela vontade de partilhar custos e riscos, pela busca de sinergia e feitas através da I\&D ou em conformidade com as restrições regulamentares ou padrões da indústria.

Ainda segundo Mention (2011), também os acordos com empresas do mesmo grupo permitem explorar o conhecimento de grupo. Além disso como são uma fonte de informação interna, esta é facilitada pela proximidade cognitiva, pela cultura comum e pela compreensão mútua do ambiente e das oportunidades, sendo uma fonte valiosa de informações em muitas pesquisas sobre inovação.

Sundbo e Gallouj (1998) consideram como fontes externas, as que são representadas por indivíduos ou organizações que sejam importantes para a empresa e que possam influenciar de alguma forma as atividades inovadoras na empresa, nomeadamente:

a) Clientes: representam os atores de maior relevância, pois mantêm um relacionamento mais intenso com o prestador de serviços;

b) Competidores: a cooperação entre os competidores em serviços contribui para o processo de inovação;

c) Governo: assume múltiplos papéis, atuando como cliente, fornecedor, competidor ou regulamentador;

d) Fornecedores: o grau de dependência de fornecedor, dependendo da atividade de serviços, influencia fortemente o processo de inovação.

As fontes de inovação ganham maior impacto em termos de produção de inovação se forem exploradas pelas empresas em cooperação. Segundo Mention (2011) a exploração conjunta de recursos e capacidades e o desenvolvimento de novos ou renovados produtos podem proporcionar uma vantagem competitiva sustentável à empresa. Através de cooperações as empresas poderão aumentar o seu fundo de recursos e obter economias de escala, evitando riscos competitivos.

As fontes de informação e as práticas de cooperação podem ser analisadas contemplando os fornecedores e clientes, fontes ou parceiros institucionais, concorrentes e outras empresas do grupo. Esta abordagem foi também investigada por Mention (2011) que procurou analisar os efeitos da cooperação e das fontes de informação (de quatro tipos de parceiros) das empresas do setor de serviços no grau de novidade da inovação, concluindo que no primeiro caso, as empresas estão envolvidas ativamente em atividades de inovação com os parceiros, enquanto no segundo, eles só beneficiam dos efeitos da difusão do conhecimento. 


\section{Egitania}

s c i e $\Omega$ c i a

\subsection{BARREIRAS À INOVAÇÃO NOS SERVIÇOS}

O Livro Verde da Inovação (CE, 1996) aponta quatro importantes barreiras à inovação: falta de orientação da investigação até à inovação; falta de recursos humanos qualificados; financiamento difícil; e o contexto jurídico e regulamentar. Mohnen e Röller (2005), Cruz (2007) vão no mesmo sentido destacando as seguintes barreiras à inovação: a falta de pessoal qualificado; a legislação, regulação de normas, padrões, e impostos e a falta de fontes de financiamento apropriadas. A estas dificuldades acrescentam a falta de oportunidades de cooperação com outras empresas e instituições tecnológicas, como fator impeditivo ao desenvolvimento de inovações. Por sua vez, o Manual de Oslo da OCDE (2005) agrupa as barreiras à inovação em três fatores: económicos, da empresa e outras razões (Tabela 2).

Também nas empresas de serviços existem barreiras que dificultam a inovação, sendo muitas vezes as suas próprias características também uma barreira. Relativamente aos serviços Preissl (1998) identifica 14 barreiras à inovação divididas em 4 categorias (Tabela 3). Além das anteriores referidas, Preissl (1998) salienta que as barreiras que mais dificultam o acesso à inovação são os fatores políticos, as suas regras e tributações que reduzem os incentivos e aumentam as dificuldades financeiras para as empresas. Estas dificuldades, consequentemente, levam à redução dos recursos disponíveis que as empresas têm para aplicar na inovação.

\begin{tabular}{|c|c|}
\hline $\begin{array}{l}\text { Fatores } \\
\text { Económicos }\end{array}$ & $\begin{array}{l}\text { - Excessivos riscos percebidos; } \\
\text { - Custo muito alto; } \\
\text { - Falta de fontes apropriadas de financiamento; } \\
\text { - Prazo muito longo de retorno do investimento na inovação. }\end{array}$ \\
\hline $\begin{array}{ll}\text { Fatores } & \text { da } \\
\text { Empresa } & \end{array}$ & $\begin{array}{l}\text { - Potencial de inovação insuficiente (I\&D, conceção); } \\
\text { - Falta de pessoal qualificado; } \\
\text { - Falta de informações sobre tecnologia; } \\
\text { - Falta de informações sobre mercados; } \\
\text { - Gastos com inovação difíceis de controlar; }\end{array}$ \\
\hline Outras Razões & $\begin{array}{l}\text { - Falta de oportunidade tecnológica; } \\
\text { - Falta de infraestrutura; } \\
\text { - Nenhuma necessidade de inovar devido a inovações } \\
\text { - } \text { anteriores; } \\
\text { - Lraca proteção aos direitos de propriedade intelectual; } \\
\text { - } \quad \text { Clientes indiferentes a novos produtos e processos. } \\
\end{array}$ \\
\hline
\end{tabular}




\begin{tabular}{|c|c|}
\hline Riscos de Mercado & $\begin{array}{l}\text { - } \text { Riscos na realização de inovações } \\
\text { - Riscos relativos ao desenvolvimento dos mercados } \\
\text { - } \quad \text { Custos imprevisíveis da inovação } \\
\text { - } \quad \text { Prazos de amortização longos } \\
\text { - } \quad \text { Elevados custos de inovaçãa }\end{array}$ \\
\hline $\begin{array}{l}\text { Restrições } \\
\text { Financeiras }\end{array}$ & $\begin{array}{l}\text { - Falta de recursos financeiros próprios } \\
\text { - Disponibilidade de empréstimos bancários e outros } \\
\text { fundos externos }\end{array}$ \\
\hline $\begin{array}{l}\text { Barreiras Legais e } \\
\text { Burocráticas }\end{array}$ & $\begin{array}{l}\text { - Longos procedimentos na administração e autorização } \\
\text { - Barreiras legais e regulamentares }\end{array}$ \\
\hline $\begin{array}{l}\text { Restrições Dentro } \\
\text { da Empresa }\end{array}$ & $\begin{array}{l}\text { - Falta de pessoal qualificado } \\
\text { - Falta de equipamento técnico } \\
\text { - Imaturidade das tecnologias } \\
\text { - Resistência interna à inovação }\end{array}$ \\
\hline
\end{tabular}

Outro fator mencionado é o facto de muitos dos apoios dados para a área da inovação estarem direcionados para a produção, excluindo à partida os serviços. A inovação tem custos elevados, por isso muitas empresas não inovam, porque para isso teriam que aumentar muito os preços dos seus serviços o que não permitiria alcançar a quantidade de clientes suficientes para que aquela inovação fosse eficiente (Preissl, 1998).

Também Sundbo e Gallouj (1998) discutem os fatores impeditivos do desenvolvimento de inovações nos serviços, agrupando-os em externos ou internos à organização. As forças externas influenciam o processo de inovação podendo ser institucionais, tecnológicas, de serviços profissionais, gerenciais ou sociais e envolvem os concorrentes, os usuários/clientes, o setor público e os fornecedores. As forças internas estão relacionadas com a administração e estratégia das atividades inovadoras, assim como outros departamentos que auxiliam a manutenção dos processos produtivos, como por exemplo os recursos humanos.

Para Escauriza et al. (2001) as barreiras ao desenvolvimento da inovação nos serviços não diferem das da indústria. Tal como na indústria também nos serviços se encontram as barreiras legais, entraves burocráticos, restrições financeiras, problemas técnicos, qualificação e gestão da inovação, as mesmas que foram apontadas por Preissl (1998) e Sundbo e Gallouj (1998).

Relativamente às barreiras legais e burocráticas, existe uma falta de proteção das inovações em serviços em comparação com o setor da indústria, dado que as patentes não são um meio de proteção muito utilizado em serviços, também os impostos reduzem os incentivos à inovação e a regulação do mercado de trabalho aumentando significativamente os custos.

Para além dos problemas financeiros, as empresas de serviços têm ainda outras dificuldades como a falta de conhecimento tecnológico, o que dificulta a seleção de projetos, as dificuldades na aquisição de equipamentos ligados à tecnologia e inovação e por vezes a falta de qualificação de gerentes e colaboradores na área da inovação, o que envolve também a absorção de certos serviços. 


\section{Egitania}

$s$ c i e $\Omega$ c i a

\section{HIPÓTESES A TESTAR}

O presente estudo tem como principal objetivo estudar o comportamento em termos de inovação das empresas de serviços dos cinco concelhos do distrito da Guarda. Pretende-se analisar se as empresas prestadoras de serviços destes concelhos têm introduzido inovações e identificar padrões comportamentais que permitam explicar que fatores contextuais estão associados aos melhores desempenhos inovadores.

Para atingir o objetivo definido, antes de mais, torna-se fundamental clarificar quais são as hipóteses a ser estudadas e que apoiaram toda a investigação e análise dos resultados. Com efeito, é essencial definir quais as hipóteses que refletem as questões teóricas relevantes, dado que estas auxiliam no sentido de canalizar a atenção do estudo para evidências relevantes (Barañano, 2008).

Face ao exposto, tendo em conta a revisão de literatura efetuada e os objetivos definidos, estabeleceram-se as seguintes hipóteses teóricas genéricas:

- H1: As Fontes de Informação influenciam a Dinâmica de Inovação das Empresas de Serviços.

- H2: Os Obstáculos à Inovação influenciam a Dinâmica de Inovação das Empresas de Serviços.

- H3: A Cooperação e o Apoio Governamental à Inovação tem influência sobre a Dinâmica de Inovação das Empresas de Serviços.

\section{FONTES DE DADOS E MÉTODOS DE ANÁLISE}

Para identificar as empresas de serviços dos concelhos em análise, utilizou-se a base de dados de empresas do Instituto Nacional de Estatística para 2009, de onde foram extraídas apenas as empresas de serviços de cinco concelhos do Distrito da Guarda: Celorico da Beira; Fornos de Algodres, Gouveia, Seia e Trancoso.

A escolha e preferência por estes concelhos deve-se ao facto destes serem próximos e contíguos, pertencerem a um distrito do interior do país, com caraterísticas e especificidades que deverão ser tidas em conta aquando da definição de politicas de inovação de âmbito territorial. Deve-se ainda ao facto de se entender que, apesar de próximos, existem hipóteses de estes concelhos não se correlacionarem da mesma forma em relação ao processo de inovação e de cooperação.

O instrumento de recolha de informação foi o inquérito por questionário. Na recolha de dados podem ser utilizados três tipos de métodos: o questionário, as entrevistas e os dados secundários (Quivy e Campeenhoudt, 2008). A opção recailu sobre o questionário, porque se pretendia analisar a perceção das empresas de serviços dos concelhos selecionados, de forma 


\section{Egitania}

$s$ c i e $\Omega$ c i a

a caracterizar regiões próximas, do interior do país e com vista a obter informação mais atualizada possível.

O questionário baseou-se nas hipóteses apresentadas no ponto anterior e foi efetuado com o objetivo de compreender se as empresas inovam ou não, os fundamentos dessa inovação, a existência de cooperação na inovação e as dificuldades em inovar. Para a elaboração do inquérito, utilizaram-se questões do CIS 2010 (Comunnity Innovation Survey) e outras que derivaram da revisão de literatura.

A população em estudo, à data da recolha dos dados, era constituída por 909 empresas de serviços: 105 pertenciam a Celorico da Beira; 83 a Fornos de Algodres, 176 a Gouveia, 378 a Seia e 167 a Trancoso.

Para calcular a dimensão adequada da amostra (n) de uma população finita, como é o caso, quando se pretende estimar uma proporção (p) utiliza-se a expressão (1), que se refere a uma amostra aleatória simples e que garante um nível de confiança $\lambda$ e um nível de precisão D.

$$
n=(p \times(1-p)) /((D 2 /(Z \alpha / 2) 2)+(p \times(1-p)) / N)
$$

Assim, para um universo (universo alvo igual ao universo inquirido) de $\mathrm{N}=909$ empresas procurou-se determinar, a dimensão da amostra representativa da população.

A proporção (p) pode assumir todos os valores no intervalo $[0,1]$ e a função $[p \times(1-p)]$ é usual assumir o valor máximo de 0,25 na hipótese mais pessimista, ou seja, quando a dispersão é máxima. Como não se conhece a proporção (p), optou-se pela hipótese otimista, isto é, p=0,1. O nível de confiança usual é $\lambda=95 \%$ e o nível de precisão $D= \pm 5 \%$. Para este nível de confiança, consultada a tabela da distribuição normal, resulta o valor de $Z \alpha / 2=1,96$.

Aplicada a fórmula (1), a amostra representativa para o universo da população é então de 120 inquéritos, repartidos proporcionalmente pelos concelhos. A proporção foi calculada com base no número de empresas de cada município, em 2009. Os inquéritos foram distribuídos (120) e recolhidos (44).

O questionário foi realizado nos meses de janeiro a novembro de 2013, pessoalmente. Assim, a amostra é constituída por 44 empresas que colaboraram no preenchimento do inquérito, representando 5\% da população.

Aplicou-se a análise estatística multivariada "k-means clusters" (Hill e Hill, 2008) para detetar padrões comportamentais das empresas de serviços face à inovação. Posteriormente, indagouse analisar as diferenças entre os vários clusters, ou seja, procurou-se caracterizar cada um dos grupos de empresas face a um conjunto de atributos, para perceber quais as diferenças observáveis entre os grupos e quais os fatores que estão associados ao melhor desempenho. Para verificar as hipóteses formuladas recorreu-se à aplicação de testes de diferenças múltiplas de médias para aferir as características únicas de cada cluster. 
Deste modo, procurou-se constituir grupos de empresas de serviços de acordo com uma escala de envolvimento em termos de objetivos que levaram as empresas a introduzir inovações para encontrar perfis ou características de cada grupo. Esta análise requer que a Anova apresente níveis de significância inferiores a 0,05; ou seja que os níveis de significância 0,000 dos testes F, de cada caso (empresas) tenha um comportamento diferenciado nos diferentes grupos.

\section{ESTUDO EMPÍRICO}

A amostra deste estudo é constituída por 44 empresas do setor dos serviços, que responderam ao inquérito, e que estão repartidas pelos cinco concelhos em análise da seguinte forma: 43\% pertencem ao concelho de Seia, 21\% ao concelho de Gouveia, 18\% ao concelho de Trancoso e 9\%, respetivamente, ao concelho de Celorico da Beira e de Fornos de Algodres.

Considerando o agrupamento dos serviços do Instituto Nacional de Estatística INE relativo à Classificação das Atividades Económicas (CAE), contata-se (Quadro 1) que das empresas inquiridas a grande maioria são empresas com atividades no Comércio por grosso e a retalho; reparação de veículos automóveis e motociclos (55\%), seguindo-se Alojamento, restauração e similares com 18\%. Às Atividades de saúde humana e apoio social; Atividades de consultoria, cientificas, técnicas e similares e outras atividades de serviços coube, respetivamente, a percentagem de 7\%. Finalmente, a Educação, as Atividades artísticas, de espetáculos, desportivas e recreativas e as Atividades imobiliárias representam cerca de $2 \%$ das empresas de serviços inquiridas.

\begin{tabular}{|c|c|c|c|c|}
\hline & Frequência & $\%$ & \% Válida & $\begin{array}{c}\% \\
\text { Cumulativa }\end{array}$ \\
\hline $\begin{array}{l}\text { G: Comércio por grosso e a retalho; reparação de } \\
\text { veículos automóveis e motociclos }\end{array}$ & 24 & 54,5 & 54,5 & 54,5 \\
\hline I: Alojamento, restauração e similares & 8 & 18,2 & 18,2 & 72,7 \\
\hline P: Educação & 1 & 2,3 & 2,3 & 75,0 \\
\hline Q: Atividades de saúde humana e apoio social & 3 & 6,8 & 6,8 & 81,8 \\
\hline $\begin{array}{l}\text { R: Atividades artísticas, de espetáculos, desportivas e } \\
\text { recreativas }\end{array}$ & 1 & 2,3 & 2,3 & 84,1 \\
\hline S: Outras atividades de serviços & 3 & 6,8 & 6,8 & 90,9 \\
\hline $\begin{array}{l}\text { M: Atividades de consultoria, científicas, técnicas e } \\
\text { similares }\end{array}$ & 3 & 6,8 & 6,8 & 97,7 \\
\hline L: Atividades imobiliárias & 1 & 2,3 & 2,3 & 100,0 \\
\hline Total & 44 & 100,0 & 100,0 & \\
\hline
\end{tabular}

Quadro 1: Atividade Económica

Relativamente ao tamanho das empresas da amostra, verifica-se que a grande maioria são microempresas, cerca de 64\% delas têm menos de 5 trabalhadores, 18\% delas têm entre 5 e 
9 trabalhadores e 11\% entre 11 a 49 trabalhadores. Apenas 7\% das empresas da amostra têm de 20 a 49 trabalhadores.

Procurou-se também saber se nas empresas, durante o período 2008 a 2012, ocorreu alguma mudança significativa, com impacto no volume de vendas em pelo menos 10\% (Quadro 2).

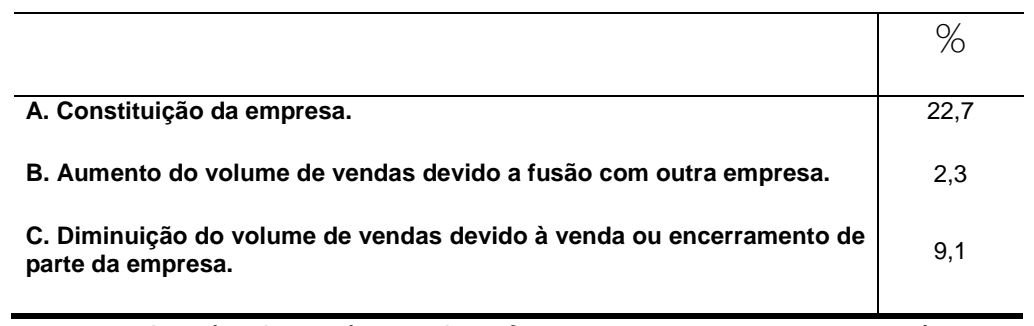

Quadro 2: Mudanças Significativas com Impacto nas Vendas

Da análise do quadro constata-se que cerca de 23\% empresas sofreram mudanças que afetaram 10\% do volume de vendas ao nível da constituição da empresas, 9\% ao nível de diminuição do volume de vendas devido à venda ou encerramento de parte da empresa e apenas 2\% delas com impacto no aumento de vendas devido a fusão com outra empresa.

Analisando se a empresa introduziu inovações (introduziu no mercado algum serviço ou método de produção ou fornecimento de serviços tecnologicamente novo ou melhorado), no período 2008-12 (Quadro 3), verifica-se que apenas 36\% delas introduziram inovações, sendo o concelho de Seia o que apresenta maior percentagem de empresas de serviços com inovações, seguindo-se o concelho de Gouveia.

\begin{tabular}{|c|c|c|c|c|c|c|c|}
\hline & & & & Município & & & \\
\hline & & $\begin{array}{c}\text { Celorico da } \\
\text { Beira }\end{array}$ & $\begin{array}{l}\text { Fornos de } \\
\text { Algodres }\end{array}$ & Gouveia & Seia & Trancoso & Total \\
\hline Não & $\mathrm{N}$ & 3 & 3 & 6 & 10 & 6 & 28 \\
\hline & $\%$ & $75,0 \%$ & $75,0 \%$ & $66,7 \%$ & $52,6 \%$ & $75,0 \%$ & $63,6 \%$ \\
\hline Sim & $N$ & 1 & 1 & 3 & 9 & 2 & 16 \\
\hline & $\%$ & $25,0 \%$ & $25,0 \%$ & $33,3 \%$ & $47,4 \%$ & $25,0 \%$ & $36,4 \%$ \\
\hline Total & $\mathrm{N}$ & 4 & 4 & 9 & 19 & 8 & 44 \\
\hline & $\%$ & $100,0 \%$ & $100,0 \%$ & $100,0 \%$ & $100,0 \%$ & $100,0 \%$ & $100,0 \%$ \\
\hline
\end{tabular}

Quadro 3: A Empresa Introduziu Inovações por Município, período de 2008-2012,

Todavia, a introdução de inovações por parte das empresas de serviços, foi fundamentalmente desenvolvida por outras empresas ou institutos. Saliente-se ainda que apenas 39\% das empresas de serviços empregam trabalhadores com ensino superior e não têm, praticamente requerido o registo de patentes, para proteger as suas inovações. 
A avaliação dos efeitos da introdução de inovações, durante o período 2008-2012, sobre o emprego de quadros superiores, quadros intermédios e operários (Quadro 4), permite constatar que não se registaram aumentos em qualquer nível de emprego. Os efeitos da inovação traduziram-se para as empresas na manutenção de emprego. A grande maioria das empresas em análise referira que mantiveram o emprego total bem como dos quadros superiores e intermédios e de operários. Cerca de 16\% das empresas assinalaram que a introdução de inovações repercutiu-se em diminuição do emprego geral, de quadros intermédios e de operários e 14\% em diminuição de quadros superiores.

\begin{tabular}{l|c|c|c|c}
\hline & A. Emprego total & $\begin{array}{l}\text { B. Emprego em } \\
\text { quadros superiores }\end{array}$ & $\begin{array}{c}\text { Emprego quadros } \\
\text { intermédios }\end{array}$ & $\begin{array}{l}\text { D. Emprego de } \\
\text { operários }\end{array}$ \\
\hline Diminui & 15,9 & 13,6 & 15,9 & 15,9 \\
Manteve-se & 84,1 & 86,4 & 84,1 & 84,1 \\
\hline
\end{tabular}

Quadro 4: Efeitos da Introdução de Inovações sobre o Emprego

Para analisar o processo de inovação nas empresas de serviços dos 5 concelhos do Distrito da Guarda escolheram-se como variáveis os objetivos que levaram as empresas a inovar, nomeadamente: Melhorar a qualidade do produto, Alargar a gama de produtos, Entrar em novos mercados ou aumentar a quota de mercado, Cumprir regulamentos ou normas, Aumentar a flexibilidade da produção, Reduzir custos da mão-de-obra, Reduzir o consumo de materiais, Reduzir o consumo de energia e Reduzir os danos ambientais. A utilização da metodologia da análise de clusters mostrou-se adequada e as variáveis, de realização de objetivos, utilizadas para classificar as empresas foram todas significativas para a solução encontrada, como se pode verificar pelos resultados da ANOVA (Quadro 5). A aplicação da análise de clusters permitiu distinguir 3 padrões comportamentais das empresas relativamente à inovação (Quadro $6)$.

\begin{tabular}{|c|c|c|c|c|c|c|}
\hline & \multicolumn{2}{|c|}{ Cluster } & \multicolumn{2}{|l|}{ Erro } & \multirow[b]{2}{*}{$\mathrm{F}$} & \multirow[b]{2}{*}{ Sig. } \\
\hline & $\begin{array}{c}\text { Média } \\
\text { Quadrática }\end{array}$ & df & $\begin{array}{c}\text { Média } \\
\text { Quadrática }\end{array}$ & df & & \\
\hline Melhorar a qualidade do produto & 5,108 & 2 & ,919 & 41 & 5,556 & ,007 \\
\hline Alargar a gama de produtos & 11,670 & 2 & 803 & 41 & 14,540 & ,000 \\
\hline $\begin{array}{l}\text { Entrar em novos mercados ou aumentar a } \\
\text { quota de mercado }\end{array}$ & 20,349 & 2 & 450 & 41 & 45,195 &, 000 \\
\hline Cumprir regulamentos ou normas & 2,986 & 2 & 459 & 41 & 6,504 & ,004 \\
\hline Aumentar a flexibilidade da produção & 14,610 & 2 & ,779 & 41 & 18,756 &, 000 \\
\hline Reduzir custos da mão-de-obra & 10,864 & 2 & 621 & 41 & 17,500 &, 000 \\
\hline Reduzir o consumo de materiais & 8,895 & 2 & 601 & 41 & 14,799 &, 000 \\
\hline Reduzir o consumo de energia & 11,954 & 2 & 487 & 41 & 24,531 &, 000 \\
\hline Reduzir os danos ambientais & 17,572 & 2 & 457 & 41 & 38,440 & ,000 \\
\hline
\end{tabular}

Quadro 5: Análise ANOVA 


\begin{tabular}{|l|c|c|c|}
\hline & Cluster 1 & Cluster 2 & Cluster 3 \\
\cline { 2 - 4 } & $\mathrm{N}=11$ & $\mathrm{~N}=15$ & $\mathrm{~N}=18$ \\
\hline Melhorar a qualidade do produto & 2,73 & 1,47 & 1,89 \\
Alargar a gama de produtos & 2,91 & 1,00 & 1,67 \\
$\begin{array}{l}\text { Entrar em novos mercados ou aumentar a quota de } \\
\text { mercado }\end{array}$ & 2,45 &, 13 &, 33 \\
Cumprir regulamentos ou normas & 2,64 & 1,67 & 2,06 \\
Aumentar a flexibilidade da produção & 2,55 &, 40 & 1,28 \\
Reduzir custos da mão-de-obra & 2,09 &, 27 & 1,28 \\
Reduzir o consumo de materiais & 2,09 &, 53 & 1,67 \\
Reduzir o consumo de energia & 2,64 &, 73 & 1,83 \\
Reduzir os danos ambientais & 2,91 &, 67 & 2,17 \\
\hline
\end{tabular}

Quadro 6: Constituição dos Clusters

O cluster 1, onde os resultados obtidos em termos de inovação são os melhores, cujos objetivos para inovar abarcam os vários campos, foi qualificado de mais inovador e proactivo. O cluster 2 apresenta os piores resultados em termos de objetivos para inovar, procurando inovar apenas para cumprir normas e regulamentos e para melhorar a qualidade do produto e foi classificado de menos inovador e com introdução de inovação apenas exigida por lei. O cluster 3, apresenta resultados médios em temos objetivos para inovar e cuja principal preocupação é inovar para reduzir os danos ambientais e cumprir regulamentos e normas foi classificado de inovador médio e reativo com responsabilidade social. $\bigcirc$ grupo 1 é constituído por 11 empresas, o grupo 2 por 15 empresas e o grupo 3 por 18 empresas.

Na sequência da análise de procedeu-se ao cruzamento de variáveis utilizando o teste de independência do Qui-quadrado, por forma, a aferir sobre a influência de variáveis contextuais, ligadas ao Município onde a empresa operava e a variáveis operacionais, ligadas à atividade principal das empresas, dimensão da empresa e disponibilização das tecnologias de informação (Quadro 7).

\begin{tabular}{|l|r|r|r|r|}
\hline & \multicolumn{1}{|c|}{ Valor } & df & \multicolumn{1}{c|}{$\begin{array}{c}\text { Asymp. Sig. } \\
\text { (2-sided) }\end{array}$} & \multicolumn{1}{c|}{ Obs } \\
\hline Atividade principal & 14,865 & 14 &, 387 & $\mathrm{X}$ \\
Município & 20,314 & 8 &, 009 & $\mathrm{~V}$ \\
\cline { 2 - 5 } Email & 6,030 & 2 &, 049 & $\mathrm{~V}$ \\
\cline { 2 - 5 } Website & 7,199 & 2 &, 027 & $\mathrm{~V}$ \\
\cline { 2 - 5 } $\begin{array}{l}\text { № Empregados escalão } \\
\text { Trabalhadores com Ensino Superior }\end{array}$ & 2,908 & 6 &, 820 & $\mathrm{X}$ \\
\cline { 2 - 5 } &, 645 & 2 &, 724 & $\mathrm{X}$ \\
\cline { 2 - 5 }
\end{tabular}

Quadro 7: Resultados do Teste do Qui-quadrado 
Os resultados deste teste permitem concluir que os aspetos ligados à localização e a disponibilização de tecnologias de informação evidenciaram influência nos resultados obtidos em termos de Inovação. Todavia, a atividade da empresa, a dimensão da empresa e o fato da empresa possuir trabalhadores com Ensino Superior não evidenciaram influência nos resultados obtidos em termos de inovação. Constata-se, assim que as empresas de Celorico da Beira predominam no cluster 1, em Fornos de Algodres e Gouveia as empresas situam-se predominantemente no cluster 2 e em Seia e Trancoso predominam as empresas no cluster 3 (Quadro 8).

\begin{tabular}{|lr|r|r|r|r|}
\hline & & \multicolumn{3}{|c|}{ Clusters } & \multirow{2}{*}{ Total } \\
\cline { 2 - 6 } & & \multicolumn{1}{|c|}{1} & 2 & 3 & \multicolumn{2}{c|}{} \\
\hline Celorico da Beira & $\%$ & 100 & 0 & 0 & 100 \\
Fornos de Algodres & $\%$ & 25 & 75 & 0 & 100 \\
Gouveia & $\%$ & 11 & 56 & 33 & 100 \\
Seia & $\%$ & 16 & 26 & 58 & 100 \\
Trancoso & $\%$ & 25 & 25 & 50 & 100 \\
Total & $\%$ & 25 & 34 & 41 & 100 \\
\hline
\end{tabular}

Quadro 8: Localização de Empresas de Serviços por Cluster

Para interpretar o modo como se estabeleceu a relação entre as variáveis explicativas e a variável dependente do processo de inovação nos serviços recorreu-se à análise das diferenças de médias dos grupos.

Relativamente às principais fontes de informação utilizadas pelas empresas de serviços para inovar (Quadro 9), os grupos 1 e 3 mais inovadores destacam-se do grupo 2 menos inovador por recorrem às mais diversas fontes de informação, quer fontes internas (provenientes de outras empresas do grupo), quer de mercado (Concorrentes, Clientes, Empresas de consultadoria), quer de fontes institucionais (Universidades ou outras instituições de ensino superior, Institutos de investigação governamentais ou instituições privadas sem fins lucrativos) quer de outras fontes mais informais (Conferências, reuniões e publicações científicas ou profissionais; Redes de informação computacionais). Saliente-se que não existem diferenças significativas entre os grupos para as fontes internas e informais provenientes da própria empresa e de feiras e mostras, respetivamente. 


\begin{tabular}{|c|c|c|c|c|c|c|}
\hline & $\begin{array}{l}\text { Soma dos } \\
\text { quadrados }\end{array}$ & df & $\begin{array}{c}\text { Média } \\
\text { Quadrática }\end{array}$ & $\mathrm{F}$ & Sig. & Obs \\
\hline Fontes internas à empresa & 1,065 & 2 & ,532 & ,379, & 687, & \\
\hline $\begin{array}{l}\text { Outras empresas pertencentes ao } \\
\text { mesmo grupo }\end{array}$ & 7,912 & 2 & 3,956 & 7,904 & ,001 & $1>3>2$ \\
\hline Concorrentes & 18,239 & 2 & 9,119 & 12,929 & ,000 & $1>3>2$ \\
\hline Clientes & 9,948 & 2 & 4,974 & 3,718 & 033 & $1,3>2$ \\
\hline Empresas de consultadoria & 10,145 & 2 & 5,073 & 9,438 & 000 & $1>3,2$ \\
\hline $\begin{array}{l}\text { Fornecedores de equipamento, } \\
\text { materiais, componentes ou software }\end{array}$ & 1,489 & 2 & 744, & ,586, & ,561 & \\
\hline $\begin{array}{l}\text { Universidades ou outras instituições } \\
\text { de ensino superior }\end{array}$ & 3,812 & 2 & 1,906 & 4,910 & ,012 & $1>3>2$ \\
\hline $\begin{array}{l}\text { Institutos de } \\
\text { governamentais ou investigação } \\
\text { privadas sem fins lucrativos }\end{array}$ & 4,364 & 2 & 2,182 & 7,343 & ,002, & $1>3,2$ \\
\hline Patentes & 2,504 & 2 & 1,252 & 2,980 & 062 & \\
\hline $\begin{array}{l}\text { Conferências, reuniões e publicações } \\
\text { científicas ou profissionais }\end{array}$ & 9,883 & 2 & 4,941 & 7,496 & ,002 & $1>3,2$ \\
\hline Redes de informação computacionais & 8,251 & 2 & 4,126 & 4,606 & ,016 & $1,3>2$ \\
\hline Feiras, mostras de produtos & 1,903 & 2 & 951 & 832 & ,443 & \\
\hline
\end{tabular}

Quadro 9: Diferenças de Médias entre Grupos - Fontes de Informação para Inovar

No que respeita aos obstáculos à inovação observa-se um menor número de diferenças entre os grupos (Quadro 10), e as que existem apresentam um padrão idêntico ao verificado em relação às Fontes para inovar. Com efeito, verifica-se que as empresas de serviços situadas no grupo 1 são as que evidenciam uma maior Falta de informação sobre mercados.

\begin{tabular}{|c|c|c|c|c|c|c|}
\hline & $\begin{array}{l}\text { Soma dos } \\
\text { Quadrados }\end{array}$ & df & $\begin{array}{c}\text { Média } \\
\text { Quadrática }\end{array}$ & $\mathrm{F}$ & Sig. & Obs \\
\hline Perceção de riscos económicos excessivos & 5,527 & 2 & 2,763 & 1,196 & ,313 & \\
\hline Custos de inovação demasiado elevados & 13,216 & 2 & 6,608 & 2,368 & , 106 & \\
\hline Falta de fontes de financiamento apropriadas & 12,913 & 2 & 6,457 & 1,978 & , 151 & \\
\hline Estrutura organizacional pouco flexível & 3,353 & 2 & 1,676 & 1,359 & ,268 & \\
\hline Falta de pessoal qualificado & 3,080 & 2 & 1,540 & 1,300 & ,283 & \\
\hline Falta de informação sobre tecnologia & 1,965 & 2 & ,982 & 1,236 & ,301 & \\
\hline Falta de informação sobre mercados & 11,304 & 2 & 5,652 & 4,147 & ,023 & $1>3>2$ \\
\hline Regulamentações e normas & 4,235 & 2 & 2,117 & ,938 & ,400 & \\
\hline $\begin{array}{l}\text { Falta de recetividade dos clientes a novos } \\
\text { produtos }\end{array}$ & 5,668 & 2 & 2,834 & 1,543 & ,226 & \\
\hline
\end{tabular}

Quadro 10: Diferenças de Médias entre Grupos - Obstáculos à Inovação 
Pode observar-se (Quadro 11) que as variáveis, relativamente à importância das patentes, da cooperação e do apoio governamental à inovação, não evidenciaram diferenças com significado estatístico. Estas variáveis não mostraram influenciar a constituição dos clusters e por isso não influenciaram o comportamento mais inovador das empresas de serviços.

\begin{tabular}{|l|r|r|r|r|r|}
\hline & \multicolumn{1}{|c|}{$\begin{array}{c}\text { Soma dos } \\
\text { Quadrados }\end{array}$} & \multicolumn{1}{c|}{ df } & \multicolumn{1}{c|}{$\begin{array}{l}\text { Média } \\
\text { Quadrática }\end{array}$} & \multicolumn{1}{c|}{$\mathrm{F}$} & \multicolumn{1}{c|}{ Sig. } \\
\hline $\begin{array}{l}\text { Durante o período entre 2008-2012, a sua empresa } \\
\text { requereu pelo menos uma patente em qualquer país? }\end{array}$ &, 067 & 2 &, 033 &, 742 &, 483 \\
$\begin{array}{l}\text { A sua empresa recebeu algum apoio governamental } \\
\text { para atividades de inovação }\end{array}$ &, 267 & 2 &, 133 & 1,018 &, 370 \\
$\begin{array}{l}\text { A sua empresa estabeleceu algum acordo de } \\
\text { cooperação para atividades de inovação }\end{array}$ &, 109 & 2 &, 054 &, 828 &, 444 \\
\hline
\end{tabular}

Quadro 11: Diferenças de Médias entre Grupos- Importância das Patentes, Apoio

Governamental e Cooperação

Todavia, pode-se ainda constatar que, embora não se registem diferenças com significado estatístico (p>0,05), as Empresas de serviços do Cluster mais inovador e mais proactivo, são as que mais requerem pelo menos uma patente e que mais receberam apoio governamental para inovar. Saliente-se ainda que os dois clusters mais inovadores mostraram maior propensão para cooperar (Quadro 12).

\begin{tabular}{|l|c|c|c|}
\hline & Cluster 1 & Cluster 2 & Cluster 3 \\
\hline $\begin{array}{l}\text { Durante o período entre 2008-2012, a sua empresa } \\
\text { requereu pelo menos uma patente em qualquer país? }\end{array}$ & $18,2 \%$ & $0,0 \%$ & $0,0 \%$ \\
\hline $\begin{array}{l}\text { A sua empresa recebeu algum apoio governamental para } \\
\text { atividades de inovação }\end{array}$ & $9,1 \%$ & $6,7 \%$ & $0,0 \%$ \\
\hline $\begin{array}{l}\text { A sua empresa estabeleceu algum acordo de cooperação } \\
\text { para atividades de inovação }\end{array}$ & $9,1 \%$ & $0,0 \%$ & $11,1 \%$ \\
\hline
\end{tabular}

Quadro 12: Patentes, Apoio Governamental e Cooperação por Cluster

Neste ponto procurou-se analisar os fatores que influenciam a inovação das empresas de serviços de cinco concelhos do distrito da Guarda, regiões de interior de Portugal, e regiões não centrais. Em ordem a explorar os fatores que influenciam a dinâmica de inovação das empresas de serviços, estabeleceram-se três hipóteses sobre a influência das fontes de informação, dos obstáculos (entraves) à inovação e da cooperação e apoio governamental sobre a dinâmica de inovação das empresas de serviços.

Da análise dos resultados constata-se que a maioria das empresas pertence ao concelho de Seia (maior concelho em análise) e são microempresas. Dentro do setor dos serviços, 


\section{Egitania}

s c i e $\Omega$ c i a

destacam-se as empresas comerciais, seguindo-se as de alojamento e restauração. Além disso, constata-se que apenas $23 \%$ delas sofreram mudanças que afetaram $10 \%$ do volume de vendas ao nível da constituição das empresas.

Em termos de inovação apenas cerca de 1/3 das empresas inquiridas introduziram inovações no período de 2008-2012, e não requereram o registo de patentes para proteger as suas inovações, porque as inovações que introduziram foram desenvolvidas por outras empresas ou institutos. Além disso, não produziram efeitos em termos de emprego, porque a grande maioria das empresas refere que se registou a manutenção de emprego.

Relativamente ao processo de inovação das empresas de serviços e dos seus padrões de inovação, os métodos quantitativos permitiram desenhar perfis comportamentais das empresas e encontrar maior ou menor proximidade entre esses padrões. Tendo em conta estes perfis, é possível inferir que as condições que estão associadas a uma atitude mais pró-ativa em termos de inovação e, por conseguinte, à melhor dinâmica de inovação são:

- as variáveis contextuais e as variáveis operacionais no que diz respeito aos aspetos ligados à localização, com realce para Celorico da Beira, e à disponibilização de tecnologias de informação (email e website);

- as fontes de informação utilizadas para inovar nomeadamente as fontes internas e de mercado, bem como fontes institucionais e outras fontes informais, confirmando assim a hipótese 1;

- os obstáculos à inovação nomeadamente a falta de informação sobre os mercados confirmando assim a hipótese 2 nesta condição;

A dinâmica de cooperação e o apoio governamental à inovação não evidenciaram diferenças com significado estatístico para a constituição dos clusters e sobre a influência em termos de dinâmica de inovação levando à rejeição da hipótese 3, todavia, foram as empresas mais inovadoras as que mais receberam apoios governamentais.

Estes resultados empíricos vão em parte de encontro aos resultados alcançados por Mention (2011) que não encontrou relação com significado estatístico entre a cooperação com concorrentes e com parceiros de mercado (fornecedores, clientes e consultores privados), e a propensão para inovar, mas que encontrou uma relação positiva entre as empresas de serviços que utilizam mais fontes de informação e a propensão para inovar. Salientado que as informações (fontes) de clientes e fornecedores estimulam a inovação.

Saliente-se que estes resultados negligenciam o papel da cooperação e dos apoios governamentais e são contraditórios com a literatura (por exemplo de Tether, 2005, Natário et al. 2012, Natário et al. 2006). Uma possível explicação pode residir na amostra que é maioritariamente constituída por empresas de comércio. A interação e cooperação das empresas deste setor com parceiros pode não conduzir a inovações. Por sua vez as empresas deste setor raramente acedem a fundos comunitários e apoios governamentais para inovar, 


\section{Egitania}

$s$ c i e $\Omega$ c i a

dada a sua reduzida dimensão e aos objetivos desses fundos comunitários que raramente são destinados a este setor.

Curiosamente, as empresas do setor de serviços que apontam a falta de informação sobre os mercados como obstáculos e dispõem das novas tecnologias (a sua ausência atua como entrave à inovação) são as mais propensas para inovar, apresentando uma melhor dinâmica de inovação. Estes resultados são consistentes com outros estudos que incorporam quer o setor de serviços quer a indústria (Natário et al. 2006).

\section{CONCLUSÕES}

O presente estudo incidiu sobre o comportamento das empresas de serviços em termos de inovação e dos fatores associados aos melhores desempenhos inovadores das empresas dos concelhos de Celorico da Beira, Fornos de Algodres, Gouveia, Seia e Trancoso.

Os resultados da análise permitem concluir, na região em estudo, dentro do setor dos serviços, destacam-se as empresas comerciais, seguidas das de alojamento e restauração. Além disso, constata-se que apenas 23\% delas sofreram mudanças que afetaram 10\% do volume de vendas ao nível da constituição das empresas.

Em termos de inovação apenas cerca de 1/3 das empresas inquiridas introduziram inovações no período de 2008-2012, valor aquém do verificado a nível nacional (cerca de 2/3 de acordo com o CIS 2010 (Direção-Geral de Estatísticas da Educação e Ciência, 2012)). As inovações que introduziram foram maioritariamente desenvolvidas por outras empresas ou instituições, contrariamente ao aferido no CIS 2010 onde predominam as atividades de inovação realizadas dentro da empresa. Além disso, não produziram efeitos em termos de emprego, porque a grande maioria das empresas refere que se registou a manutenção de emprego. Das empresas prestadoras de serviços estudadas 39\% empregam profissionais com estudos a nível do ensino superior.

Relativamente aos padrões de inovação nas empresas de serviços em regiões de interior, regiões não centrais, identificaram-se três perfis comportamentais: o cluster 1, mais inovador e proactivo; o cluster 2, o menos inovador e com introdução de inovação apenas exigida por lei e o cluster 3, como reativo e com responsabilidade social.

Os fatores que estão associadas a uma atitude mais pró-ativa em termos de inovação e, por conseguinte, à melhor dinâmica de inovação são: as variáveis contextuais e as variáveis operacionais ligadas à localização e à disponibilização de tecnologias de informação; as fontes internas e de mercado, as fontes institucionais e outras fontes informais de informação utilizadas para inovar e a falta de informação sobre os mercados como principal obstáculo à inovação. Saliente-se que a nível nacional, no setor de serviços, e de acordo com o CIS 2010, os principais fatores que dificultaram as atividades de inovação foram os custos com a inovação demasiado elevados (33\%), a insuficiência de capitais próprios ou do grupo a que pertence (27\%) e a falta de financiamento de fontes externas (25\%). 


\section{Egitania}

$s$ c i e $\Omega$ c i a

Como se pode constatar os resultados alcançados no estudo distanciam-se da média nacional, o que pode justificar-se por as empresas de serviços estarem situadas em regiões de interior, tendencialmente afastadas dos grandes centros de consumo, com mercados de reduzida dimensão e com maior dificuldade em aceder a mercados mais distantes, quer ainda por não haver, nestas regiões estruturas que apoiem na dinamização de mercados internos. Todavia, relativamente às diversas fontes para inovar são as empresas de serviços mais inovadoras que mais importância dão quer às diversas fontes, sendo consistente com o se verifica no estudo de Mention (2011). Neste caso, pode afirmar que os resultados não sofreram o efeito interioridade, concluindo-se que há mais propensão a inovar quando as empresas de serviços utilizam as mais diversas fontes de informação.

A dinâmica de cooperação e o apoio governamental à inovação não evidenciaram diferenças com significado estatístico para a constituição dos clusters e sobre a influência em termos de dinâmica de inovação, todavia, foram as empresas mais inovadoras as que mais receberam apoios governamentais. Estes resultados em parte justificam-se ainda pelo facto de constatar que as empresas do setor dos serviços apresentarem valores de cooperação muito próximos e tendencialmente reduzidos. Além disso, embora os resultados alcançados pelas empresas de serviços, em termos de cooperação, tenham ido de encontro aos alcançados por Mention (2011), contrariam a literatura, bem como os apoios governamentais para inovar, o que pode ficar a dever-se a estas empresas serem maioritariamente do comércio e se situarem em regiões de interior com especificidades próprias, nomeadamente baixa densidade relacional.

Os resultados deste estudo proporcionam um contributo positivo quer em termos teóricos quer em termos práticos, sobre os fatores que influenciam o processo e dinâmica de inovação nas empresas de serviços em regiões não centrais, de interior. Do ponto de vista teórico, o trabalho alerta para resultados que vão de encontro à literatura sobre a inovação e outros que a contrariam. Em particular, os resultados empíricos evidenciam de forma clara que as empresas de serviços necessitam de possuir e utilizar as tecnologias de informação, bem como de aceder e combinar as diferentes fontes de informação e conhecimento e obter mais informação sobre os seus mercados a fim de alcançar níveis mais elevados de inovação. De realçar a influência das fontes de informação provenientes do mercado de clientes e fornecedores, as fontes de informação institucionais e as fontes informais sobre a dinâmica de inovação. Em suma, estes resultados confirmam empiricamente que a utilização de diversas e diferentes fontes de informação e conhecimento para inovar e a disponibilização de tecnologias e conhecimento de mercados fornecem às empresas de serviços uma vantagem competitiva em termos de inovação.

Os resultados deste estudo têm também implicações para os gestores, consultores e decisores políticos, cuja missão é organizar, apoiar ou criar as condições adequadas para a inovação nas empresas de serviços, em regiões de interior. Na medida em que os resultados confirmam a influência das fontes de informação de mercado, institucionais e informais, os gestores das empresas de serviços devem dar particular importância a estas de informação. Para isso devem afetar recursos para melhor explorar as fontes informações, através de estudos de mercado sobre as expectativas e necessidades dos clientes ou feedbacks diretos de clientes, da 


\section{Egitania}

$s$ c i e $\Omega$ c i a

intensificação das relações com instituições públicas (de pesquisa e de ensino) sobre os resultados de investigação e pesquisa, e da participação em conferências, reuniões científicas e profissionais para aceder às novidades do mercado. Os gestores devem também pôr em prática os mecanismos e ferramentas (novas tecnologias de informação: email e website) que permita a partilha de conhecimentos e reduzir o efeito interioridade e aumente o conhecimento dos seus mercados. Embora a cooperação direta com os parceiros quer empresariais quer institucionais não seja atualmente uma prática generalizada no setor de serviços, os resultados indiciam que ela estimula claramente a inovação e deve, portanto, ser intensificada. Além disso, os gerentes e consultores devem definir as suas estratégias de cooperação e de fontes de informações, de acordo com os objetivos perseguidos: de melhorar a qualidade dos produtos, alargar a gama e entrar em novos mercados ou de reduzir custos e cumprir com a legislação.

As conclusões sobre a necessidade de, em regiões de interior (não centrais), as empresas de serviços terem de intensificar a introdução de inovações, reduzir os obstáculos que enfrentam para inovar, nomeadamente através de um melhor conhecimento dos mercados e sobre o papel que a cooperação e os apoios governamentais têm em geral para estimular a inovação, para alcançar valores próximos da média nacional e reduzir o seu gap de inovação e competitividade, requerem por parte dos decisores públicos um papel ativo e uma preocupação crescente. Assim, os decisores políticos poderiam reforçar a política de cooperação e apoio às empresas para estimular as empresas a envolver-se em parcerias público-privadas com agentes de investigação para ajudar a desenvolver os seus processos de inovação, e para apoiar na identificação e conhecimento dos seus mercados. Além disso, como são empresas de muito pequena dimensão, poderiam criar instrumentos de apoio ao conhecimento e dinamização de mercados, através de estudos de mercados efetuados pelas instituições de pesquisa local e procurando aproximar estas do tecido empresarial.

Umas das principais limitações verificadas no desenvolvimento deste projeto prende-se com a dificuldade no acesso à informação por via de inquérito. Esta limitação tornou o processo de recolha dos inquéritos muito lenta, uma vez que acabou por ser feito presencialmente em formato papel, com todos os custos daí inerentes.

Uma outra condicionante deste estudo deveu-se ao facto da amostra ser reduzida, face ao definido pelos métodos de amostragem, 44 por oposição aos 120 definidos, o que tem implicações ao nível da generalização das conclusões.

Apesar das limitações, acredita-se que este estudo apresenta um contributo positivo para uma melhor compreensão sobre a inovação nos serviços, particularmente em regiões que não são grandes centros urbanos.

Como o tema da inovação nos serviços é relativamente recente e pouco aprofundado acreditase que, por esse motivo, este estudo possa servir como ponto de partida a outros mais que o possam desenvolver e aprofundar de forma a tornar este tema mais explícito.

Como sugestão para futuros projetos sobre a mesma temática, considera-se importante o estudo da inovação de serviços, mas com particular extensão aos serviços públicos. 


\section{Egitania \\ s c i e $\Omega$ c i a}

Procurando verificar se os padrões de inovação nas regiões de interior são semelhantes ou

diferentes dos registados noutras regiões mais centrais.

\section{REFERÊNCIAS}

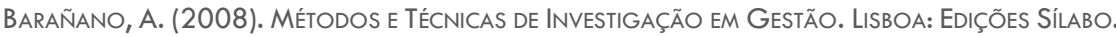

Barata, J. (2011). InOVação nos Serviços: Conceitos, Modelos e Medidas: Uma Aplicação no Sector Bancário. Teaching EConomics Working PAPERS. UNIVERSIDAde TÉCNICA DE LISBOA. INSTITUTO dE ECONOMIA E GESTÃO. LISBOA.

Barras, R. (1986). TOWARdS a TheOry Of InNOVAtion IN Services. Research Policy, 15, pp. 161-173.

Bloch, C. \& Bugge, M. (2013). Public Sector innovation - from theory to Measurement. Structural Change and Economic DYNAMICS, 27, PP. 133- 145.

Camacho, J. \& Rodriguez, M. (2005). How Innovative are Services? Analysis for Spain. University of Granade. Spain: The Service INDUSTRIES JOURNAL, $25, \mathrm{~N}^{\circ} 2$.

CE (1996). Livro Verde Sobre a Inovação. Dezembro. Bruxelas.

Coombs, R. \& Miles I.(2000). Innovation, Measurements and Services: The New Problematique in J. S. Metcalfe e I. Miles (editors), innovation Systems in the Service Economy: Measurement and Case Study Analysis, Economics of Science, Technology and INNOVATION, USA: KLUWER ACADEMIC PUBlisher, 18, PP.85-103.

Cruz, S. (2007). Inovação em Portugal: O Caso do Sector da Construção. TeSe de Mestrado. Aveiro: Universidade de Aveiro.

Djellal, F.; Gallouj, F. \& Miles, I. (2013). Two Decades of Research on Innovation in Services: Which Place for Public Services? Structural Change and EConomic Dynamics, 27, pp. 98-117.

Drejer, I. (2004). Identifying InNovation Surveys Of Service: A SChumpeterian Perspective. Research Policy, 33, pp.551-562.

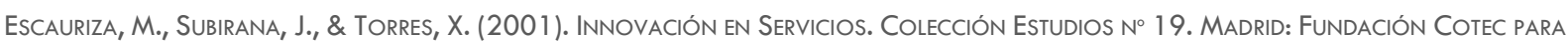
LA INNOVACIÓN TECNOLÓGICA.

FonseCa, S. (2010). Cooperação no Âmbito da InOVação Empresarial: Estudo nas Empresas de Serviços Portuguesas. TeSE de Mestrado. Guarda: InStituto Politécnico da Guarda.

Gallouj F. (2010). Services InNovation: Assimilation, Differentiation, InVERsion and Integration. In Bidgoli, H. (ED), The Handbook of Technology Management. Chapter 75. John Wiley and SONS.

Gallouj, F. \& Weinstein, O. (1997). Innovation in Services. Research Policy, 26, pP.537-556. Paris: University of Paris.

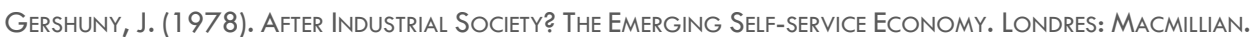

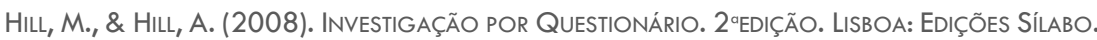

Hipp, C. \& Grupp, H. (2005). Innovation in the Service Sector: The Demand for Service-specific Innovation Measurement Concepts AND TYPOLOGIES. RESEARCH POLICY, 34, PP. 517-535.

Mention, A. (2011). Co-operation and Co-opetition as Open Innovation Practices in the Service Sector: Which Influence on INNOVATION NOVElty? TECHNOVATION, 31(1), PP.44-53.

Miles, I. (2001). Services InNOVAtion: A Reconfiguration of InNOVAtion Studies. PREST. Discussion Paper, 01-05. University OF MANCHESTER. 


\section{Eqgitania \\ $s$ c i e $\Omega$ c i a}

Miles, I. (2005). InNOVAtion in Services. In Fageberg, J.; MOWery, D. \& Nelson, R.. The Oxford Handbook of Innovation. Oxford: OXFORD UNIVERSITY PRESS, PP. 433-468.

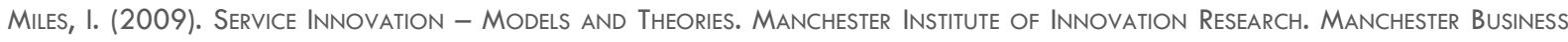
SCHOOL. THE UNIVERSITY OF MANCHESTER.

MOHNen, P. \& Röller, L. (2005). COMPLEMENTARITIES IN INNOVATION POLICY. EUROPEAN ECONOMIC ReVIEW, 49, PP. 1431 - 1450.

Natário, M. M.; Neto, P.A. \& Reigado, F. M. (2006). Attitudes to Territorial Innovation Processes in Raia Central Ibérica. in Vaz, T. N.; Morgan, E.J.\& NiJkamp, P., (eds), The New European Rurality: Strategies for Small Firms, Ashgate, Cap. 13, Part IV, pp.259-288.

Natário, M., Braga, A.; Couto, J. \&Tiago, T. (2012). Territorial Standards for Innovation: Analysis for the Regions of Portugal. ReVISTA De Estudios ReGIONAles. № 95, pP. 15-38.

OCDE (2005). Oslo Manual: Proposed Guidelines for Collecting and Interpreting TeChnOlogical InNOVAtion Data. Paris: OCDE.

Preissl, B. (1998). Barriers to InNovation In Services. Topical Paper, SI4S. Oslo: Step Goup.

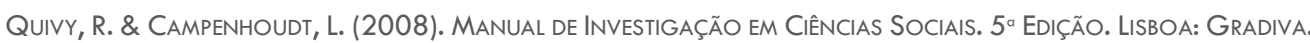

Salter, A. \& Tether, B. (2006). Innovation in Services. Through the Looking Glass of Innovation Studies. Advanced Institute of MANAGEMENT.

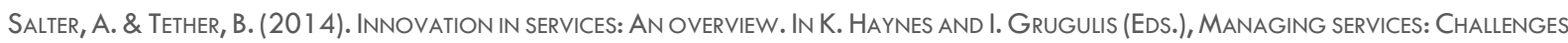
AND INNOVATIONS. OXFORD: OXFORD UNIVERSITY PRESS.

Sarkar, S. \& Carvalho, L. (2006). Inovação no Sector dos Serviços: Uma nova Área de investigação. Revista de encontros CIENTÍFICOS, 2, PP. $52-59$.

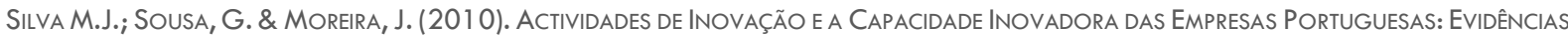
empíricas ao Nível do Sector dos Serviços, Proceedings of XX Luso - Spanish Conference on Management, 4-5 February, 2010, instituto Polttécnico de Setúbal, Portugal.

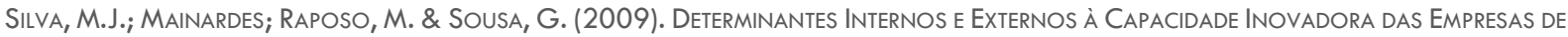

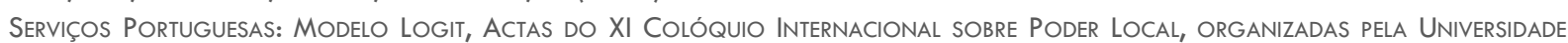
Federal da Bahia, Fundação Escola de Administração da UfBa, Salvador - Bahia- Brasil.

Smith, A. (1776). An Inquiry into the Nature and Caufes of the Wealth of Nations. London Edition, Vol. 1.

Sundbo, J. \& Gallouj, F. (1998). Innovation as loosely Coupled Systems in Services.Topical Paper, Si4S. Oslo: Step Goup.

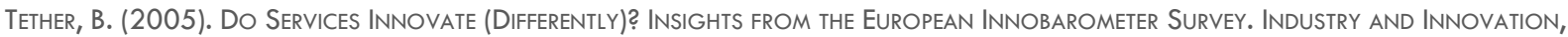
12 , No 1, PP. 153-184.

Toivonen, M. \& TuOminen, T. (2009). Emergence Of InNOVAtions In Services. The SerVice Industries Journal, 29, pp. 887-902.

UE (2010). CIS 2010. Center for SCience And Higher Education. Ministry of SCience and TeChnology. Lisboa. Portugal.

UE (2012). Cis 201 2. Center for SCience and Higher Education. Ministry of SCience and TeChnOlogy. lisboa. Portugal.

Vries, (E.), (2006). Innovation in Services in Networks of Organizations and In the Distribution of Services. Research Policy, 35, PP.1037-1051. 